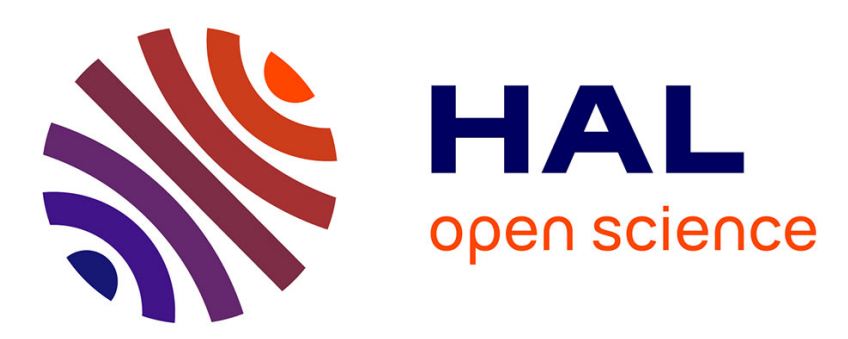

\title{
Time-varying Predictability in Crude Oil Markets: The Case of GCC Countries
}

\author{
Mohamed El Hedi Arouri, Duc Khuong Nguyen, Thanh Huong Dinh
}

\section{To cite this version:}

Mohamed El Hedi Arouri, Duc Khuong Nguyen, Thanh Huong Dinh. Time-varying Predictability in Crude Oil Markets: The Case of GCC Countries. 2010. hal-00507822

\section{HAL Id: hal-00507822 \\ https://hal.science/hal-00507822}

Preprint submitted on 1 Aug 2010

HAL is a multi-disciplinary open access archive for the deposit and dissemination of scientific research documents, whether they are published or not. The documents may come from teaching and research institutions in France or abroad, or from public or private research centers.
L'archive ouverte pluridisciplinaire HAL, est destinée au dépôt et à la diffusion de documents scientifiques de niveau recherche, publiés ou non, émanant des établissements d'enseignement et de recherche français ou étrangers, des laboratoires publics ou privés. 


\title{
Time-varying Predictability in Crude Oil Markets: The Case of GCC Countries
}

\author{
Mohamed El Hedi Arouri \\ LEO, Université d'Orléans and EDHEC Business School, mohamed.arouri@univ-orleans.fr \\ Rue de Blois - BP 6739, 45067 Orléans cedex 2, France \\ Phone: +33238492410-Fax: +33238417380 \\ Thanh Huong Dinh \\ b IRG, University of Paris-Est Cre'teil Val-de-Marne, Route de Choisy, 94010, France
}

\section{Duc Khuong Nguyen}

ISC Paris School of Management, France, dnguyen@groupeisc.com

22, Boulevard du Fort de Vaux, 75017 Paris, France

Phone: +33140539999-Fax: +33140539898

\begin{abstract}
This paper uses a time-varying parameter model with generalized autoregressive conditional heteroscedasticity effects to examine the dynamic behavior of crude-oil prices for the period 1997-2008. Using data from four countries of the Gulf Cooperation Council, we find evidence of short-term predictability in oil-price changes over time, except for several short sub-periods. However, the hypothesis of convergence towards weak-form informational efficiency is rejected for all markets. In addition, we explore the possibility of structural breaks in the time-paths of the estimated predictability indices and detect only one breakpoint, for the oil markets in Qatar and United Arab Emirates. Our empirical results therefore call for new empirical research to further gauge the predictability characteristics and the determinants of oil-price changes.
\end{abstract}

Keywords: oil price behavior, weak-form efficiency, Kalman filter.

JEL Classification: Q41, G14 


\section{Introduction}

Oil is one of the world's most important commodities and serves as the underlying assets in the trading of various financial derivatives instruments. One should bear in mind the importance of oil when looking at the reactions of the global economy and financial markets to information concerning any disruptions in global oil supply. Understanding crude-oil price dynamics is thus of great interest to many economic agents.

Stimulated by the fact that oil prices have experienced wide swings and high volatility during recent decades, a significant number of empirical works have extensively examined the links between oil prices, economic growth, and stock markets. It is widely agreed that the increases in oil prices correlate negatively with economic growth, non-oil firm-performance, and stock market activities in most oil-importing developed and emerging countries (see, e.g., Jones and Kaul, 1996; Hamilton, 1983; Basher and Sadorsky, 2006; Zhang, 2008; Lardic and Mignon, 2008; Lescaroux and Mignon, 2008; Driesprong et al., 2008). The aforementioned links are sensitively different for oil industries and net oil-exporting countries where some evidence of positive relationships has been documented (Hammoudeh and Li, 2004; Maghyereh and Al-Kandari, 2007; Arouri and Rault, 2009). Another important finding is that economic variables may be nonlinearly associated with oil-price movements as well. For instance, Zhang (2008) employs a nonlinear model to investigate the relationship between oil-price shock and economic growth in Japan, and shows the existence of nonlinearities and asymmetric linkages between the two variables studied. Lardic and Mignon (2008) reach the same conclusion for other developed economies from an asymmetric cointegration approach. With regard to oil and stock markets, Jones and Kaul (1996) show that aggregate stock market returns in four developed countries 
(the United States, Canada, Japan, and United Kingdom) are negatively related to oil price shocks. In a related study, Basher and Sadorsky (2006) find supporting evidence for the significant influence of oil-price risk on stock market returns in emerging countries. Additionally, some studies have analyzed the impact of oil-price movements from sectoral perspectives and reported that oil prices do not affect different industries in the same ways (see, e.g., El-Sharif et al., 2005; Hammoudeh and Li, 2004; Boyer and Filion, 2007; Nandha and Faff, 2008). There is also evidence of a long-term equilibrium relationship between various oil benchmark prices having different physical properties and locations (Hammoudeh et al., 2008).

Questions about the informational efficiency of crude-oil markets have been, however, less investigated than other issues, despite its important implications for traders' future actions on their portfolios and for policymakers on their energyinvestment and energy-consumption policies. Misleading information may therefore damage their interests. To get a further insight into how important is such a concept, it is opportune to recall that an efficient market generally refers to a market situation in which all available and relevant information are fully and instantaneously reflected in a security's market price so that no one can take advantage of these information. ${ }^{1}$ Accordingly, there are neither undervalued nor overvalued assets in an efficient market, and market price of financial assets constitutes a proper guide for capital budgeting and allocation. That is why market efficiency is desirable and central to asset pricing models and investor's investment decision-making process, meanwhile it

\footnotetext{
${ }^{1}$ Based on the nature of available information, Fama $(1970,1991)$ distinguishes three forms of market efficiency: strong form, semi-strong form, and weak-form efficiency. The set of available information refers to both public and private information for the strong-form efficiency, but it is limited to all public information for the semi-strong form and to all past price movements for the weak form.
} 
rests on strong assumptions such as, frictionless markets, information availability and transparency, investor rationality and arbitrage.

In the literature of energy finance, discussions concerning the efficiency of crudeoil markets began with the work of Green and Mork (1991). These authors test the hypothesis according to which the official prices of crude-oil contracts are efficient in the sense of Fama (1970), i.e., the price of a futures contract on crude oil is an efficient predictor of the ex-post spot price at the time of merchandise delivery, if all the relevant information was available at the time when the contract was set up. Using the generalized method of moments to make inferences about the predictability of monthly oil prices (Mideast Light and African Light/North Sea crudes), Green and Mork (1991) reject the weak-form efficiency for the whole sample period 19781985, but provide evidence of efficiency improvements over time when sub-sample periods are used. Maslyuk and Smyth (2008) also examine the efficiency of crude oil markets by analyzing the weekly spot and futures prices for both US West Texas Intermediate (WTI) and UK Brent benchmark crudes over the period from January 1991 to December 2004. The authors employ Lagrange Multiplier unit root tests allowing for one and two structural breaks, and find that each of the oil-price series contains a random walk. It then follows that the crude oil markets they studied were efficient in the weak form. ${ }^{2}$ Shambora and Rossiter (2007) assert the validity of the efficient market hypothesis by applying an artificial neural network (ANN) model to the daily prices of NYMEX crude oil futures contracts. ${ }^{3}$ Evidence from several technical trading rules established on the basis of their ANN model shows significant

\footnotetext{
${ }^{2}$ Some papers have used conventional unit root tests (without structural breaks) to address the efficiency of WTI and Brent crude oil markets (Sivapulle and Moosa, 1999; Tabak, 2003; Serletis and Rangel-Ruiz, 2004). Their empirical results generally support the validity of weak-form efficiency as successive stock price changes are random variables, implying that futures price changes cannot be predicted from past price changes in a meaningful way.

${ }^{3}$ See Ashenwald et al. (2002) for detailed discussions of artificial neural network models and their applications in economics and finance.
} 
predictability in the futures market for oil, which is clearly inconsistent with the work of Maslyuk and Smyth (2008). Taking a different approach, Tabak and Cajueiro (2007) investigate the time-varying degrees of long-range dependence in the Brent and WTI crude-oil returns over the period from May 1983 to July 2004. They estimate the Lo (1991)'s modified Hurst exponent by rescaled range analysis which corrects for short-term autocorrelations, and find that crude-oil markets have become more efficient over time. By implementing a de-trended fluctuation analysis to reduce the effects of nonstationarities and trends in the estimation of the Hurst exponents, Alvarez-Ramirez et al. (2008) confirm the findings of Tabak and Cajueiro (2007) in that crude-oil markets converge towards weak-form efficiency over the long term. Furthermore, their results are consistent with the existence of the timevarying short-term predictability reported in Elder and Serletis (2008).

The present paper aims to contribute to the debate about the efficient behavior of crude-oil markets by focusing attention on the four main petroleum-exporting countries of the Gulf Cooperation Council (GCC): Kuwait, Qatar, Saudi Arabia, and United Arab Emirates (UAE). One of the most important motivations for studying these countries is that they are major suppliers of oil in world energy markets and represent a very promising area for international portfolio diversification. In addition, to the best of our knowledge none of the previous studies has investigated informational efficiency in GCC oil-exporting countries. ${ }^{4}$ At the empirical level, we suggest the use of a time-varying parameter model to investigate whether selected GCC crude-oil markets converge towards weak-form market efficiency over time. From an econometric point of view, this approach relies on the estimation of a dynamic linear

\footnotetext{
${ }^{4}$ Recent studies in the energy economics literature have shifted their attention to the GCC countries, but their focus is mainly on the short- and long-term links between oil price, economic growth, and equity markets (Hammoudeh and Eleisa, 2004; Zarour, 2006; Maghyereh and Al-Kandari, 2007; Lescaroux and Mignon, 2008; Arouri and Rault, 2009).
} 
model with unobserved components based on the application of the Kalman filter technique. It allows us to study the convergence of crude oil prices towards efficient prices over time and to examine the speed of this convergence process while controlling for the presence of conditional heteroscedasticity and leptokurtic distribution of crude-oil returns. Compared to the related literature, our contribution is primarily related to the work of Tabak and Cajueiro (2007) and Alvarez-Ramirez et al. (2008) in the sense that we are also interested in the dynamics rather than the average behavior of crude-oil prices, but our methodology is different. This then allows us to compare the results obtained across studies.

Our empirical results indicate that crude-oil price changes in the countries studied behave in accordance with the weak-form efficiency hypothesis only at the beginning of the period we study. We then find strong evidence of short-term predictability of oil-price changes for almost all of the period, with no tendency to converge towards weak efficiency. Furthermore, contrary to the expectations that sudden changes may occur in the evolving efficiency measure, our test documents only one breakpoint, for the oil markets in Qatar and UAE. Theses breakpoints do not appear to correlate exactly with any of the world's main petroleum or political events.

The remainder of this paper is organized as follows. Section 2 describes the empirical method we use to model the dynamics of crude-oil prices and to explore the possibility of sudden changes in oil-price predictability indices. Section 3 presents the data and discusses the results obtained. Section 4 concludes the paper and suggests some policy implications arising from the results. 


\section{Empirical method}

\subsection{A state space model for time-varying predictability}

As discussed above, market informational efficiency stipulates that the price of an asset instantaneously reflects all available information that is relevant about the asset's intrinsic value. The latter is usually approximated by the present value of all the future cash flows the investors expect to receive. The verification of market efficiency mainly implies that securities are exchanged in public markets at their fair value and that no abnormal returns can be earned by using information already available to everyone. Further, investment styles and trading strategies such as market timing, technical analysis, or fundamental analysis do not permit investors to outperform the market, and, generally speaking, higher returns are obtained only by making riskier investments.

Although the theory of market efficiency applies to all kinds of financial securities, academic and practitioner discussions of its validity have mostly focused on equity and foreign-exchange markets. In this paper we shift our attention to crude-oil markets and examine their weak-form efficiency, according to which future returns cannot be predicted from past returns. The methodology we use here to detect predictable patterns in oil returns rests on the estimation of a time-varying autoregressive model with unobserved parameters. The rationale for doing so is that the GCC countries have, over the past two decades, accelerated and deepened policy reforms to create a favorable business environment, promote non-oil growth, and open their markets to foreign investments. Prudent fiscal and monetary policies, coupled with the resilient supervision of banking system as well as the adherence to international standards and codes, are also implemented to reduce their high degree of dependence to oil price shocks and oil revenues (Fasano and Iqbal, 2003). All in all these efforts 
would permit to substantially decrease market frictions, which ultimately leads to expect that oil prices behave more efficiently over time.

More explicitly, let $P_{i, t}$ be the crude-oil price at time $t$ in a given country $i$ where we wish to test the weak-form market efficiency, and $r_{i, t}$ the oil continuouslycompounded returns computed as $r_{i, t}=\ln \left(P_{i, t} / P_{i, t-1}\right)$; we further assume that the oil return's dynamics can be modeled by the following system of equations:

$$
\begin{aligned}
& r_{i, t}=\beta_{i, t}^{(0)}+\beta_{i, t}^{(1)} r_{i, t-1}+\varepsilon_{i, t} \\
& \varepsilon_{i, t}=h_{i, t} z_{i, t} \\
& h_{i, t}=\alpha_{i}^{(0)}+\alpha_{i}^{(1)} \varepsilon_{i, t-1}^{2}+\alpha_{i}^{(2)} h_{i, t-1} \\
& \beta_{i, t}^{(k)}=\beta_{i, t-1}^{(k)}+\eta_{i, t}^{(k)}, k=0,1
\end{aligned}
$$

In these formulas, $\beta_{i, t}^{(0)}$ and $\beta_{i, t}^{(1)}$ respectively measure, for country $i$, the longterm trend and the potential serial dependency of crude-oil returns. They are allowed to change over time according to a first-order random-walk process described in Equation (4). The idea behind this dynamic modeling is that the time values of these unobserved factors are a function of underlying market fundamentals that drive crude oil price formation. $h_{t}$ represents the conditional variance of model residuals $\left(\varepsilon_{i, t}\right)$, which is assumed to follow the standard GARCH $(1,1)$ specification proposed by Bollerslev (1986). ${ }^{5} z_{i, t}$ and $\eta_{i, t}^{(k)}$ represent random noises, assumed to be normally distributed with a mean of zero and respective variances of 1 and $V_{i}^{(k)}$. In order to apply the Kalman filter, the innovations in Equation (1) are further assumed to be

\footnotetext{
${ }^{5}$ We tested different ARCH/GARCH models and chose the GARCH $(1,1)$ specification for all countries' volatility processes according to commonly-used information criteria (Bayesian Information Criterion and Akaike Information Criterion). For the sake of concision, the test results are not reported here, but they are available under request addressed to the corresponding author.
} 
uncorrelated with those in Equation (4), i.e., $E\left(\varepsilon_{i, t}, \eta_{i, t}^{(k)}\right)=0$. It is worth noting that we intentionally employ a first-order autoregressive process to model the time-series dependence structure of oil-price returns, since all relevant information for asset pricing must be accurately and instantaneously incorporated in the latest price according to the hypothesis of weak-form efficient markets.

Under the null hypothesis of weak-form efficiency in crude-oil markets, the values of estimated $\beta_{i, t}^{(1)}$ must be equal to zero or statistically insignificant for all time periods. Accordingly, our model is reduced to a special case where crude oil price follows a random and unpredictable path, that is:

$$
\ln \left(P_{i, t}\right)=\beta_{i, t}^{(0)}+\ln \left(P_{i, t-1}\right)+\varepsilon_{i, t}
$$

Overall, the model offers the possibility of inferring a direct and time-varying measure of weak-form efficiency for crude-oil markets. As the model parameters change, we might observe a movement from inefficient to efficient states or viceversa depending on the actual market conditions (e.g., market microstructure, trading mechanism, costs, and information availability) as well as the behavior of crude-oil market participants (e.g., arbitrageurs, speculators, producers, and policymakers). Typically one would see the crude-oil price movement towards efficiency if the market under consideration experiences increased transparency and information quality, increased liquidity, and reduced trading costs through time. The proposed measure is also meaningful for reflecting the evolving characteristics of these markets owing to the gradual impacts of structural reforms. In addition, the model is general in the sense that it contains the case of a constant parameter model when $V_{i}^{(k)}$ does not fluctuate over time. In the literature, Zalewska-Mitura and Hall (1999) show that, within the Kalman filter framework, the model is powerful enough to effi- 
ciently detect changes in time-varying degrees of market efficiency, except for the first few observations. This empirical method has been applied to assess the ongoing informational efficiency in some emerging and frontier-emerging equity markets (see, e.g., Rockinger and Urga, 2000; Jefferis and Smith, 2005; Fontaine and Nguyen, 2006).

Given the state space form of our model with equations (1) and (4) being the measurement and state equations respectively, the Kalman filter algorithm can be appropriately implemented to estimate the unobserved state vector $\beta_{i, t}^{(k)}$. In principle, the Kalman filter recursively delivers the optimal estimator of the system's current states, depending on the information available at that time, by a two-step process. It first calculates the expectations of the unobserved state vector based on previously available information, and then updates the state vector when a new observation becomes available. To obtain estimated values of the set of other unknown parameters $\Phi=\left(V_{i, t}^{(k)}, \alpha_{0}, \alpha_{1}, \alpha_{2}\right)$, we have to construct a log-likelihood function based on the Kalman gain under the normality assumption (see, Harvey, 1993). Estimation of the model is then carried out by using the Quasi-Maximum Likelihood (QML) method which provides asymptotic and robust estimates even though the conditional returns are not normally distributed.

\subsection{Test of structural change}

We now explore the possibly sudden changes in the time-paths of the estimated oilreturn predictability series $\beta_{i, t}^{(1)}$. Following Bai and Perron (2003), we consider a linear regression model of the following form:

$$
\beta_{i, t}^{(1)}=\delta_{0}+\delta \beta_{i, t-1}^{(1)}+e_{i, t}
$$


If there are $m$ multiple structural breaks $\left(n_{1}, \ldots, n_{m}\right)$ in the time-path of $\beta_{i, t}^{(1)}$, the problem of dating structural breaks consists of finding the breakpoints $\left(\hat{n}_{1}, \ldots, \hat{n}_{m}\right)$ that minimize the objective function $\left(\hat{n}_{1}, \ldots, \hat{n}_{m}\right)=\arg \min _{\left(n_{1}, \ldots, n_{m}\right)} R S S_{n}\left(n_{1}, \ldots, n_{m}\right)$ where $R S S_{n}$ is the resulting residual sum of squares issued from the $m$ linear regressions of Equation (7). Note that $e_{i, t}$ is assumed to be independent and identically distributed according to a normal distribution with a mean of zero and a variance of $\sigma^{2}$.

Accordingly, we test the null hypothesis of 'no structural break' against the alternative of an unknown number of breaks given some specific upper bound $M$ $(1 \leq m \leq M)$ where $M$ is arbitrarily set equal to 5 . Whenever $m$ exceeds this upper bound, a higher value is thereby chosen. The Bayesian Information Criterion (BIC) is employed, as suggested by Bai and Perron (2003), to determine the optimal number of breaks, i.e., the number corresponding to the lowest BIC score.

\section{Data and results}

This section first presents the data used and their stochastic properties. We then discuss the empirical results of the evolving efficiency test as well as the Bai and Perron (2003) test for unknown multiple breaks in the time-varying predictability indices that we estimated in the first stage.

\subsection{Data}

We obtained the crude-oil price data from the Energy Information Administration (EIA). The data are the weekly spot FOB prices, expressed in dollars per barrel, for four OPEC and GCC countries: Kuwait, Qatar, Saudi Arabia, and UAE. The study period, which runs from February 7, 1997 to November 14, 2008, covers the recent episodes of sharp fluctuations in crude-oil prices. 
Table 1. Descriptive statistics and correlation matrix

\begin{tabular}{|c|c|c|c|c|c|c|c|c|c|}
\hline \multirow[t]{2}{*}{ Panel A } & \multicolumn{9}{|c|}{ Descriptive statistics } \\
\hline & Mean $(\%)$ & Std. dev. & Min. & Max. & Skew. & Kurt. & IQ & $\mathrm{J}-\mathrm{B}$ & $\mathrm{ARCH}(3)$ \\
\hline Kuwait & 0.143 & 0.041 & -0.168 & 0.193 & -0.452 & 4.836 & 0.050 & $106.972^{+}$ & $7.597^{+}$ \\
\hline Qatar & 0.148 & 0.037 & -0.152 & 0.163 & -0.518 & 4.703 & 0.046 & $101.517^{+}$ & $9.471^{+}$ \\
\hline Saudi A. & 0.141 & 0.043 & -0.166 & 0.176 & -0.546 & 4.362 & 0.055 & $77.845^{+}$ & $9.294^{+}$ \\
\hline UAE & 0.145 & 0.038 & -0.164 & 0.177 & -0.562 & 5.057 & 0.045 & $141.141^{+}$ & $7.720^{+}$ \\
\hline \multirow[t]{3}{*}{ Panel B } & \multicolumn{9}{|c|}{ Correlation matrix } \\
\hline & \multicolumn{5}{|c|}{ Pairwise correlations } & \multicolumn{4}{|c|}{ Spearman-rank correlations } \\
\hline & Kuwait & Qatar & Saudi A. & UAE & & Kuwait & Qatar & Saudi A. & UAE \\
\hline Kuwait & 1.000 & & & & Kuwait & 1.000 & & & \\
\hline Qatar & $0.972^{* * *}$ & 1.000 & & & Qatar & $0.973^{* * *}$ & 1.000 & & \\
\hline Saudi A. & $0.928^{* * *}$ & $0.922^{* * *}$ & 1.000 & & Saudi A. & $0.933^{* * *}$ & $0.924^{* * *}$ & 1.000 & \\
\hline UAE & $0.975^{* * *}$ & $0.967^{* * *}$ & $0.918^{* * *}$ & 1.000 & UAE & $0.976^{* * *}$ & $0.962^{* * *}$ & $0.918^{* * *}$ & 1.000 \\
\hline
\end{tabular}

Notes: this table provides the basic statistics of weekly crude-oil returns for four OPEC countries. Data are spot FOB prices in US dollars per barrel over the period from February 7, 1997 to November 14, 2008. They include mean (Mean), standard deviation (Std. dev.), minimum (Min.), maximum (Max.), skewness (Skew.), kurtosis (Kurt.), and interquartile Q3-Q1 (IQ). J-B refers to the empirical statistic of the Jacque-Bera test for normality. $\mathrm{ARCH}(3)$ is the empirical statistic of the Lagrange Multiplier test for ARCH in the residuals, which considers three lagged values chosen using information criteria. ${ }^{+}$indicates that the null hypothesis of normality and no-ARCH effects is rejected at the $1 \%$ level. ${ }^{* * *}$ indicates that correlation coefficients are significant at the $1 \%$ level.

Descriptive statistics of weekly oil returns as well as their pairwise and Spearmanrank correlation coefficients are reported in Table 1. Qatar's crude-oil returns experienced the highest average $(0.148 \%)$ over the study period, followed closely by UAE (0.145\%), Kuwait (0.143\%), and Saudi Arabia (0.141\%). None of the crude-oil return series are normally distributed, and are subject to ARCH effects, according to the results of the Jacque-Bera's test for normality and the Lagrange Multiplier test for conditional heteroscedasticity. These findings fully support our choice to use a standard GARCH specification for modeling certain stylized aspects of crude-oil returns such as fat tails, and time-varying and persistent volatility.

With regard to correlation coefficients between different crude-oil returns (see Panel B, Table 1), they are consistently above 0.91 for both pairwise and Spearmanrank correlations, and all are significant at the $1 \%$ level. High correlations are observed between three market pairs: Qatar/Kuwait (0.972), Qatar/UAE (0.967), and Kuwait/UAE (0.975). It should be noted that Spearman-rank correlation is also a 
measure of statistical association between random variables, but it performs better than the pairwise correlation when the variables considered are non-normal, which is the case for our crude-oil return series. These results suggest that the various oil prices have practically the same dynamics, and differences in their dynamical adjustment process might simply be due to variations in the oil-exporting country's specificities, oil quality, and transaction and transportation costs.

Figure 1. 24-week rolling first-order autocorrelation of crude-oil returns
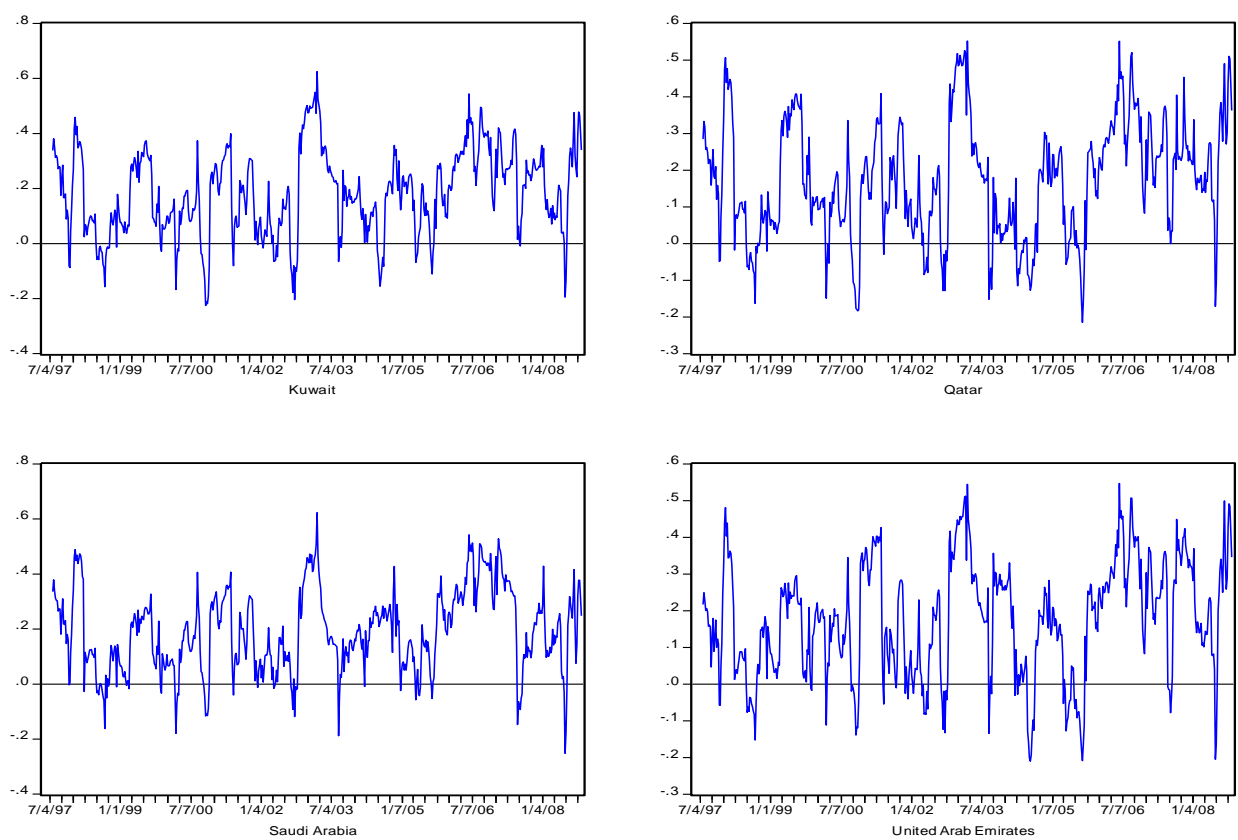

To further apprehend the short-term dynamics of crude-oil return series over time, we also proceed to calculate the rolling first-order autocorrelations for each of the countries included in our study ${ }^{6}$. The results for a 24 -week rolling window are presented in Figure 1. We observe that rolling autocorrelations combines alternative periods of negative and positive values, with however a dominance of positive values in particular at the end of the sample period. These finding suggest some predictabili-

\footnotetext{
${ }^{6}$ We gratefully acknowledge one of the anonymous referees for this helpful suggestion. We indeed calculated rolling autocorrelations for crude-oil return series of four GCC countries on several rolling windows (12 weeks, 24 weeks, and 48 weeks). However, only the 24 -week rolling autocorrelations are reported to conserve spaces since the results obtained are not much different.
} 
ty in the series dynamics and thus the rejection of the efficiency weak-form. However, apart some periods where there was an increase in autocorrelation coefficients (e.g., December 27, 2002 - April 11, 2003; and July 9, 2006 - May 2, 2007), the level of predictability is not very high in general. These results should be compared with the outcomes of our more robust econometric method, the Kalman Filter.

It is interesting to note that the changing patterns of 24-week rolling autocorrelations are somewhat similar for two pairs of markets among our sample, Kuwait/Saudi Arabia on the one hand, and Qatar and UAE on the other hand.

\subsection{Time-varying short-term predictability in oil markets}

Table 2 reports the results obtained from estimating our time-varying coefficient model for crude-oil markets in four OPEC oil-exporting countries. We immediately observe that the average value of $\beta_{i, t}^{(0)}$ coefficients, ranging from -0.092 (Saudi Arabia) to -0.001 (Kuwait), is negative and very close to zero. This suggests a low level of oil-return predictability related to other potential explanatory variables omitted from the model. Moreover, these coefficients remain relatively stable over time since the estimated value of $V_{i, t}^{(0)}$ is quite small. When tested against zero using a standard t-test, based on the model's statistical inferences, they appear to be insignificant almost all of the time. ${ }^{7}$ We can, therefore, conclude that crude-oil returns are not particularly sensitive to macroeconomic effects and other non measurable factors such as political events and external shocks. The fact that crude-oil prices have been free of controls and set by market-based pricing system since the late 1980s contributes largely to this observed price behavior.

\footnotetext{
${ }^{7}$ The complete test results are available upon request addressed to the corresponding author.
} 
With regard to the coefficients $\beta_{i, t}^{(1)}$ whose variations indicate the time-varying predictability (autocorrelation) levels in crude-oil returns, their averages are not very different across markets and stand around 20\% (19.423\% in Qatar, 20.509\% in UAE, $21.469 \%$ in Kuwait, and $21.917 \%$ in Saudi Arabia). Similar to the behavior of $\beta_{i, t}^{(0)}$ coefficients, the estimated values of $\beta_{i, t}^{(1)}$ also display little fluctuation over time since their variance $V_{i}^{(1)}$ approaches zero, with an exception being the UAE crude-oil market.

Table 2. Estimation results from the state space model with GARCH effects

\begin{tabular}{|c|c|c|c|c|}
\hline & Kuwait & Qatar & Saudi Arabia & $\mathbf{U A E}$ \\
\hline \multicolumn{5}{|c|}{ Conditional mean equation } \\
\hline $\begin{array}{l}\beta_{i}^{(0)}(\text { in } \%) \\
\beta_{i}^{(1)}(\text { in } \%) \\
\end{array}$ & $\begin{array}{l}-0.001 \\
(0.006) \\
21.469 \\
(0.056) \\
\end{array}$ & $\begin{array}{l}-0.071 \\
(0.005) \\
19.423 \\
(0.059) \\
\end{array}$ & $\begin{array}{l}-0.092 \\
(0.005) \\
21.917 \\
(0.053) \\
\end{array}$ & $\begin{array}{l}-0.066 \\
(0.006) \\
20.509 \\
(0.055)\end{array}$ \\
\hline \multicolumn{5}{|l|}{ State equations } \\
\hline $\begin{array}{l}V_{i}^{(0)}(\times 10) \\
V_{i}^{(1)}\end{array}$ & $\begin{array}{l}0.000 \\
(0.000) \\
0.004 \\
(0.007) \\
\end{array}$ & $\begin{array}{l}0.001 \\
(0.000) \\
0.007 \\
(0.007) \\
\end{array}$ & $\begin{array}{l}0.001 \\
(0.000) \\
0.000 \\
(0.007) \\
\end{array}$ & $\begin{array}{l}0.000 \\
(0.000) \\
0.000 \\
(0.012) \\
\end{array}$ \\
\hline \multicolumn{5}{|c|}{ Conditional variance equation } \\
\hline$\alpha_{i}^{(0)}(\times 10)$ & $\begin{array}{l}0.006^{* * *} \\
(0.000)\end{array}$ & $\begin{array}{l}0.005^{* * *} \\
(0.000)\end{array}$ & $\begin{array}{l}0.006^{* * *} \\
(0.000)\end{array}$ & $\begin{array}{l}0.003^{* * *} \\
(0.000)\end{array}$ \\
\hline$\alpha_{i}^{(1)}$ & $\begin{array}{l}0.109^{* *} \\
(0.045)\end{array}$ & $\begin{array}{l}0.102^{* *} \\
(0.042)\end{array}$ & $\begin{array}{l}0.116^{* * *} \\
(0.039)\end{array}$ & $\begin{array}{l}0.265^{* * *} \\
(0.052)\end{array}$ \\
\hline$\alpha_{i}^{(2)}$ & $\begin{array}{l}0.615^{* * *} \\
(0.000)\end{array}$ & $\begin{array}{l}0.479^{* * *} \\
(0.000)\end{array}$ & $\begin{array}{l}0.758^{* * *} \\
(0.000)\end{array}$ & $\begin{array}{l}0.558^{* * *} \\
(0.000)\end{array}$ \\
\hline$\alpha_{i}^{(1)}+\alpha_{i}^{(2)}$ & 0.724 & 0.581 & 0.874 & 0.823 \\
\hline Likelihood value & 1110.711 & 1171.899 & 1079.345 & 986.478 \\
\hline
\end{tabular}

Notes: the estimated model takes the following form:

$$
\begin{aligned}
& r_{i, t}=\beta_{i, t}^{(0)}+\beta_{i, t}^{(1)} r_{i, t-1}+\varepsilon_{i, t} \quad \text { (Conditional mean) } \\
& \varepsilon_{i, t}=h_{i, t} z_{i, t} \\
& h_{i, t}=\alpha_{i}^{(0)}+\alpha_{i}^{(1)} \varepsilon_{i, t-1}^{2}+\alpha_{i}^{(2)} h_{i, t-1} \quad \text { (Conditional variance) } \\
& \beta_{i, t}^{(k)}=\beta_{i, t-1}^{(k)}+\eta_{i, t}^{(k)}, k=0,1 \quad \text { (State vector) }
\end{aligned}
$$

The standard deviations of estimated parameters are given in parenthesis. For the estimated parameters in the conditional mean equation, we report their averages since they are allowed to vary over time. The significance of these coefficients ( $\beta_{i}^{(1)}$ in particular) in each time period is examined by using a standard t-test and shown in the graphs of time-varying predictability (see, Figures from 2 to $5) .^{*},{ }^{* *}$, and ${ }^{* * *}$ indicate the significance of estimated parameters at the $10 \%, 5 \%$, and $1 \%$ levels respectively. 
It is equally important to note that the $\operatorname{GARCH}(1,1)$ specification successfully captures the leptokurtic behavior and conditional heteroscedasticity in crude-oil returns for all four markets. Indeed, the coefficients of the conditional volatility equations are highly significant and satisfy the theoretical stability conditions, i.e., $\alpha_{i}^{(0)} \succ 0$, and $\alpha_{i}^{(1)}$ and $\alpha_{i}^{(1)} \geq 0$. We do not, however, find strong evidence supporting the persistence of crude-oil volatility over time since the sum $\left(\alpha_{i}^{(1)}+\alpha_{i}^{(2)}\right)$ is effectively lower than 0.9 in all cases.

To further explore the changing patterns in the estimated predictability indices, we plot their time-paths in Figures from 2 to 5. They are represented by a solid line and their 95-percent confidence intervals by dotted lines. A market is said to be weakform efficient whenever the zero line is located within the estimated confidence intervals. In this case, the time-varying coefficients of oil-return autocorrelations do not differ significantly from zero, or equivalently one cannot predict future oil prices from using past price information. Otherwise, the oil market is in inefficient state, and profitable trading opportunities may exist, based for example on technical analysis of oil price patterns. Weekly changes in crude-oil prices are also depicted, to demonstrate the joint dynamics of oil returns and their predictable nature.

Figure 2. Oil-return dynamics versus evolving efficiency in the Kuwait crude-oil market 
a) Weekly oil price changes

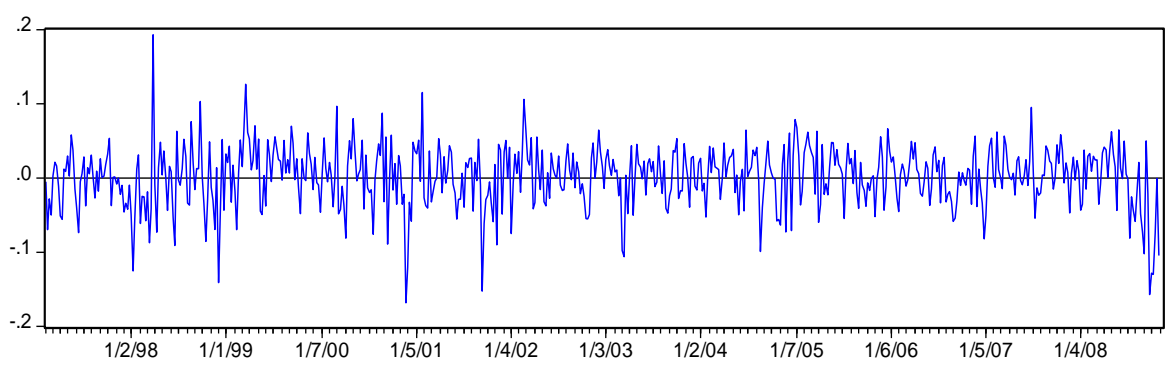

b) Time-varying predictabilityindexwith $95 \%$ confidence intervals

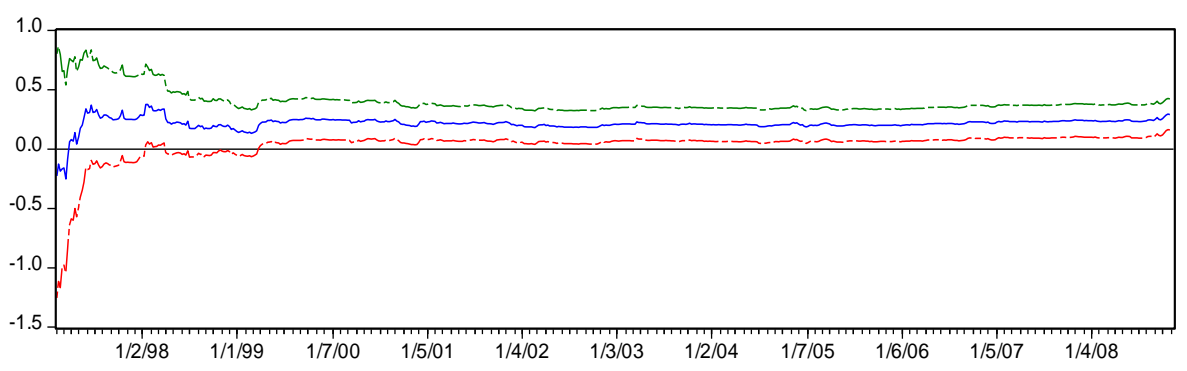

The crude-oil market in Kuwait appears to be weakly efficient over a relatively short period at the beginning of the study period, i.e., from February 7, 1997 to April 2, 1999. Note also that the period from January 16, 1998 to March 27, 1998 was marked by an inefficient behavior of oil prices in this market. After April 9, 1998, this market becomes informationally inefficient until the end of the study period without any tendency to converge towards weak-form efficiency. This indicates that oil-price movements in Kuwait can be predicted from their past values.

Figure 3. Oil-return dynamics versus evolving efficiency in the Qatar crude-oil market 

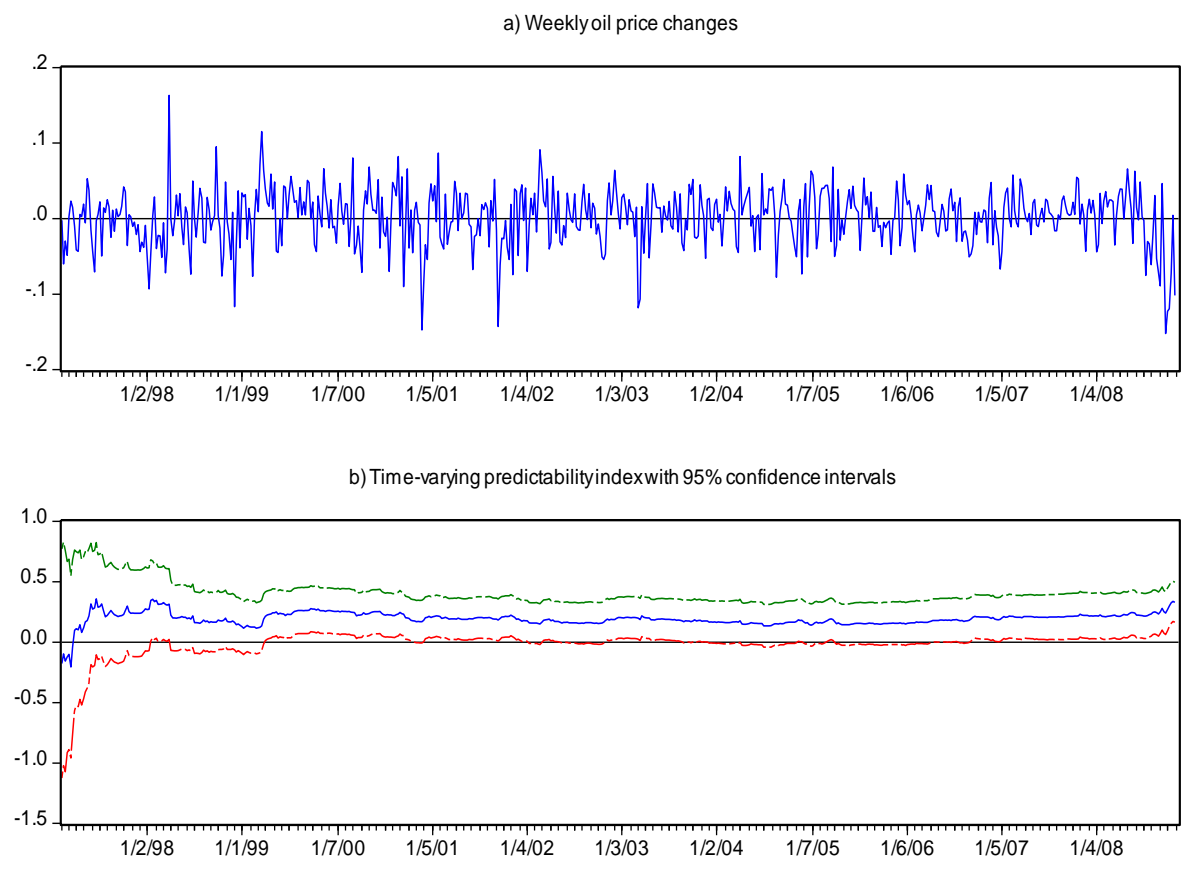

Turning now to Figure 3, we observe that oil-price changes in Qatar seem to display the same behavior as those in Kuwait. After two short sub-periods of efficiency (i.e., from February 7, 1997 to January 9, 1998 and from April 3, 1998 to March 26, 1999), this market experienced alternating periods of efficiency and inefficiency from April 2, 1999 onwards. Not only there is no evidence that the crude-oil market in Qatar is moving towards an efficient state, but also the magnitude of correlatedreturn fluctuations is greater at the end of the study period. Accordingly, technical analysis of oil-return dynamics has meaningful forecasting power in the Qatar crude oil market. One may expect more market distortions and unfavorable conditions that impede informational efficiency over the recent years when attempting to explain this time profile.

Figure 4. Oil-return dynamics versus evolving efficiency in the Saudi Arabian crude oil market 
a) Weekly oil price changes

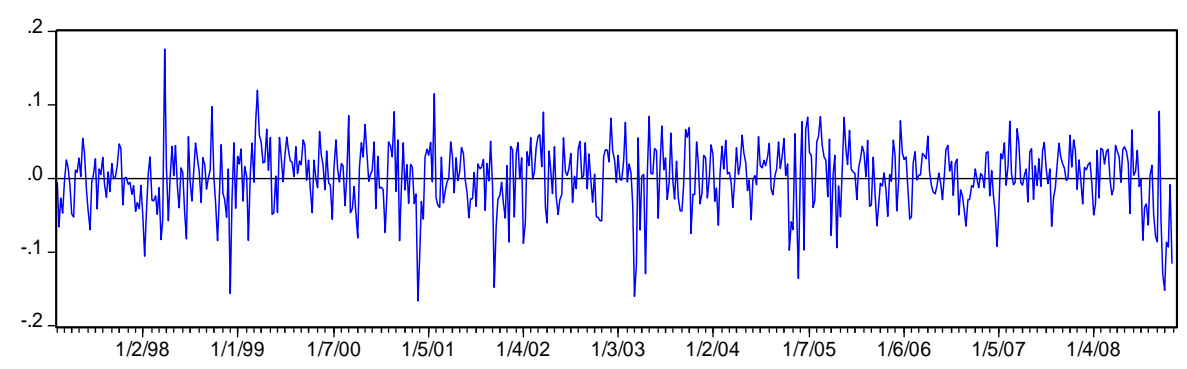

b) Time-varying predictabilityindexwith $95 \%$ confidence intervals

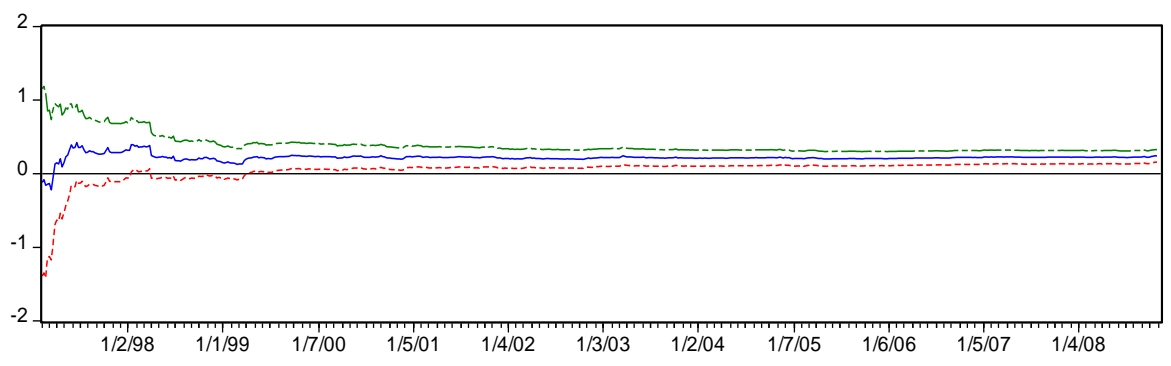

Figure 4 depicts the trajectory followed by the coefficient $\beta_{i, t}^{(1)}$ for Saudi Arabia. It shows that autocorrelations of weekly crude-oil returns display time variations and have become apparently significant after April 2, 1999. The Saudi market, with a continuum appreciation of the predictable coefficients at the end of the period, is far from any level of efficiency. These results indicate the presence of substantial shortterm predictability, since past movements in crude-oil prices enable the prediction of from $20 \%$ to $24 \%$ of the changes in future prices.

The pattern followed by the predictability index of the UAE market is quite similar to those of Kuwaiti and Saudi markets (see, Figures 2 and 4). This market begins with an efficient behavior over the period from February 07, 1997 to March 19, 1999. After this period, it becomes inefficient and remains in this pattern up to the end of the whole sample because $\beta_{i, t}^{(1)}$ is substantially different from zero and has a slightly raised level. Additionally, there is, as we can observe a pronounced trend of moving away from weak efficiency.

Figure 5. Oil-return dynamics versus evolving efficiency in the UAE crude oil market 


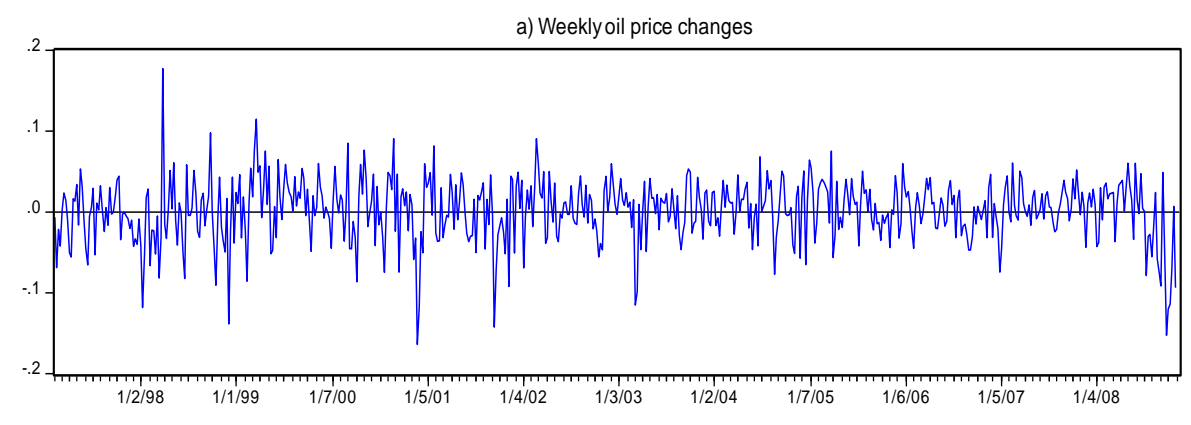

b) Time-varying predictability index with $95 \%$ confidence intervals

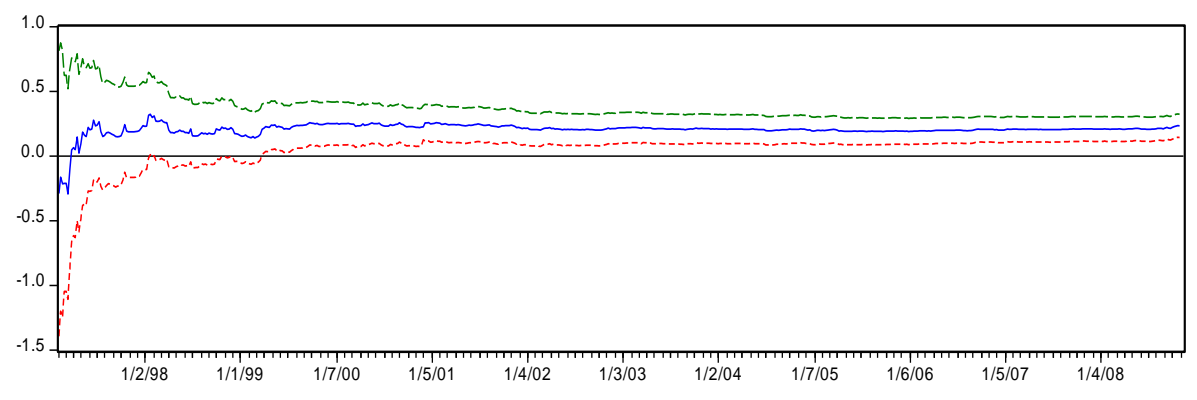

Of the previous findings, two stylized facts emerge from our investigation of the time-varying predictability in crude-oil returns. First, crude-oil markets in the GCC countries are generally more efficient inside the period February 1997 - April 1999 than afterwards. This period was particularly associated with a sharp drop in crudeoil prices, and oil-production quota cuts by the OPEC in response to the unexpected and serious impact of the Asian crisis ${ }^{8}$. The decline in production activity and thus oil consumption of Asian economies and Asian Pacific region was responsible for the most part of this price reaction. As major oil-exporters of the OPEC, our sample countries were effectively affected by these oil-market events. In this context, their relatively higher efficiency can be potentially explained by the absence of price controls, geopolitical tensions, and other significant market imperfections such as leveraged trading and speculations, compared to the later period. These conditions would

\footnotetext{
${ }^{8}$ Average weekly spot FOB prices of the OPEC has declined from their recent high of $\$ 24.72$ per barrel, reached in January, 1991, to about \$10.5 per barrel in March 20, 1998. OPEC was forced to cut quotas by 1.25 million barrels per day in April, 1998 and another 1.335 million in July, 1998. Crudeoil price continued its decreasing trend through December, 1998.
} 
lead to a more broadly market-based price in which the current crude-oil price fluctuates closely around its fundamental value.

Second, all markets we study exhibit predictable patterns almost since the mid1999 and display no convergence tendency towards efficient state, except for several short periods where market efficiency hypothesis cannot be rejected. A distinction should be noted for the case of Qatar where efficient and inefficient states alternate quite frequently. It is possible to remark that the inefficiency of our sample markets coincides with the boom period in international crude-oil markets, starting with the oil-price recovery in early 1999 and growing gradually to its highest level established in June 2008, except for a slight decrease following the internet bubble burst in 2000 and the World Trade Center terrorist attack in 2001. The reasons why crude-oil price increased substantially include essentially the recovery of the world economy, driven by rapid growth in emerging market economies (e.g., particularly those in Asian and Latin American regions such as China, India, Argentina, and Brazil). As for the fact that crude-oil markets in the GCC moves away from efficiency, this can be, more or less, justified intuitively by the presence of geopolitical risks, irrational expectations and high speculations about oil supply and demand. The first factor has arisen from the US military intervention in Iraq beginning on March 2003, the growing international tensions over Iran's nuclear programs, and the political instability in the Middle East region. The last two factors have strongly risen in recent years due particularly to the fact that the OPEC and other oil-exporting countries attempted to keep the oil prices at the high level in order to generate oil revenues ${ }^{9}$. This then leads to

\footnotetext{
${ }^{9}$ This behavior is comprehensive to the extent that most of the OPEC country members have been and are facing significant economic challenges, of which the question of how to diversify their economies and thus reduce their dependence to oil revenues is of great importance. Structural reform programs, albeit they have been progressively implemented, did not achieve the expected results.
} 
increased activity of hedge funds and speculators in the derivatives markets for crude oil. Although the creation of energy derivatives markets helps promoting information dissemination, and improving the amount of information available for crude-oil pricing as well as market liquidity through lower trading costs and arbitrage activity, it does increase the oil volatility (see, e.g., Fleming and Ostdiek, 1999), whose level is not justified by changes in the oil-price fundamentals such as global supply and demand of oil.

Summarizing all, our empirical results reveal that the dynamic pattern of predictability is somewhat similar across the four countries we consider. The hypothesis that crude-oil markets reached a higher level of weak efficiency cannot be confirmed. Moreover, none of them has displayed signs of evolving towards an efficient state, because the oil-return autocorrelations become more and more prominent and significant as the end of the estimation period approaches. Finally, we find no evidence of substantial variations in predictability though time. These findings are consistent with the results of our rolling autocorrelation analysis (sub-section 3.1) and with those of Elder and Serletis (2008), who show unambiguous evidence of short-term predictability in crude-oil returns from a semi-parametric wavelet-based approach, and Alvarez-Ramirez et al. (2008), who cannot reject the presence of meaningful autocorrelations in the Brent (North Sea - Europe), WTI (USA), and Dubai (UAE) crude-oil price returns for time horizons shorter than one month by estimating the DFA-augmented (Detrended Fluctuation Analysis) Hurst exponent.

\subsection{Explanation of sudden changes}

As shown in Figures 1, 2, and 3, crude-oil returns in the four countries studied have experienced a number of large increases and decreases. These changes are commonly 
explained by major developments and reforms in the oil industry (e.g., crude oil markets have been gradually deregulated beginning in the 1980s), the considerable increase in industrial investment activities dependent on oil-based energy, the impact of oil-price regulation policies, and the influences of wars, political events, embargoes, and revolutions. Tabak and Cajueiro (2007) present a list of significant social, economic, and political events that might strongly affect crude-oil price movements, such as the Yom Kippur war that started in 1973, the Iranian revolution between 1978 and 1980, and the Gulf War of the early 1990s. Taken together, they raise the question of whether crude-oil prices are subject to structural changes in their dynamics. If so, and to the extent that oil-price movements have direct implications for the short-term efficient behavior of oil returns, we should observe sudden breaks in the time-paths of our predictability measures.

Table 3. Results of structural change test

\begin{tabular}{|c|c|c|c|c|c|}
\hline & $\begin{array}{l}\text { Number of } \\
\text { theoretical } \\
\text { breaks }(m)\end{array}$ & BIC score & $\begin{array}{l}\text { Number of } \\
\text { structural } \\
\text { breaks }\end{array}$ & $\begin{array}{l}\text { Estimated } \\
\text { break dates }\end{array}$ & $\begin{array}{l}95 \% \text { confidence } \\
\text { intervals for break } \\
\text { dates }\end{array}$ \\
\hline \multirow{6}{*}{ Qatar } & 0 & -3305.518 & \multirow{6}{*}{1} & \multirow{6}{*}{$\begin{array}{l}\text { November } \\
6,1998\end{array}$} & \multirow{6}{*}{$\begin{array}{l}\text { [October 16, 1998; } \\
\text { September 8, 2000] }\end{array}$} \\
\hline & 1 & -3311.479 & & & \\
\hline & 2 & -3294.057 & & & \\
\hline & 3 & -3277.155 & & & \\
\hline & 4 & -3259.262 & & & \\
\hline & 5 & -3240.106 & & & \\
\hline \multirow{6}{*}{ UAE } & 0 & -1823.794 & \multirow{6}{*}{2} & \multirow{6}{*}{$\begin{array}{l}\text { March 19, } \\
1999\end{array}$} & \multirow{6}{*}{$\begin{array}{l}\text { [March 12, 1999; } \\
\text { September 24, 1999] }\end{array}$} \\
\hline & 1 & -1897.417 & & & \\
\hline & 2 & -1926.881 & & & \\
\hline & 3 & -1916.075 & & & \\
\hline & 4 & -1906.644 & & & \\
\hline & 5 & -1892.707 & & & \\
\hline
\end{tabular}

Notes: this table reports the results of the Bai and Perron (2003) test for unknown multiple structural breaks in a linear regression framework. The optimal number of breaks corresponds to the one having the lowest BIC (Bayesian Information Criterion) score.

The Bai and Perron (2003) test for multiple structural breaks was performed for all four crude-oil markets considered and the results obtained are summarized in Table 3. We detect one breakpoint for the crude-oil market in Qatar on November 6, 1998, and one breakpoint for the crude-oil market in the UAE on March 19, 1999. 
Structural changes are not seen in the time-variations of predictability measures for Kuwait and Saudi Arabia.

Once the breaks are observed, it is naturally interesting to investigate the potential factors underlying their occurrence. As we can see however, both observed breaks in Qatar and the UAE do not coincide exactly with any particular event in world and regional oil history, but their $95 \%$ confidence intervals do cover several important oil events such as OPEC's announcements of oil-production cutbacks of 1.245 million barrels per day on March 31, 1998 (effective on April 1, 1998), and of 1.355 million barrels per day on June 24, 1998 (effective on July 1, 1998). The occurrence of these structural changes was also coupled with promises from non-OPEC nations (e.g., Mexico, Oman and Russia) to reduce their oil production. These measures, which have been undertaken together by world oil producers in response to the decline in global oil demand following the advent of the financial crisis in July 1997, are likely to change the nature of crude-oil price dynamics in the Qatari and UAE markets. Indeed, crude-oil price recorded its lowest level since the early 1990s for Qatar in December 1998 ( $\$ 10.15$ per barrel) and for the UAE in February 1999 (\$9.83 per barrel), but it was then tripled between January 1999 and September 2000 and experienced its upward dynamics until July 2008. Aside from this argument, structural breaks in Qatar and the UAE can be further explained by the fact that Asian countries are the primary export markets for their oil products, which is not the case for other GCC countries of our sample ${ }^{10}$. Therefore, sudden drops in energy consumption of Asian countries due to economic slowdowns strongly affect both countries' oil exports, and may ultimately lead to shifts in the oil-predictability behavior. The rela-

\footnotetext{
${ }^{10}$ Our calculations from the Arab Monetary Fund's statistics reveal that in 1998 the Asia's top three importers from Qatar count for 69\% (Japan 52\%, Singapore 9\%, and South Korea 8\%), compared to $46 \%$ for the UAE (Japan 30\%, South Korea 10\%, India 6\%), and 36\% for Saudi Arabia. Data for Kuwait are not available in 1998, but the Asia's top two importers from Kuwait represent about 40\% in 1997 and $31 \%$ in 1999.
} 
tively lesser dependence of the UAE on Asian oil importers may explain the fact that the estimated break date in the UAE lags behind the break we detected in Qatar.

Note finally that our empirical method was also applied to a more recent weekly dataset covering the period from January 7, 2000 to January 8, 2010 as the last decade was marked by a specific oil-price dynamics, i.e., the period of soaring oil prices ${ }^{11}$. It appears however that the results obtained for the 2000-2010 period are not different from those we present in the paper. They can be summarized as follows: $i$ ) all crude-oil markets are not weak-form efficient since January 2000 and onwards; $i$ ) none of the predictability indices is subjected to structural change, just confirming our findings for the period 1997-2008.

\section{Conclusion}

This paper employs a time-varying parameter model with GARCH effects, based on the Kalman filter framework, to examine the time-variations in the short-term predictability (autocorrelations) of crude-oil price returns. The rationale for doing this is that international oil markets have evolved significantly since the petroleum shocks of the early 1970s, and a competitive market has been progressively established by the continuing movement towards structural reform in the major oil-exporting countries. There are now internationally-accepted prices for both crude and refined oil products. Oil markets are being further deregulated, and market frictions such as price controls and restrictions on trade are gradually being removed, improving the efficiency of oil markets. In this regard, one may expect that oil prices have evolved towards a more efficient behavior over time according to the theory of financial market efficiency. It should also be noted that this oil-market situation is one particularly

\footnotetext{
${ }^{11}$ We thank the referees for suggesting this robust check of our empirical results. The findings for the period 2000-2010, albeit not reported here, are available under request.
} 
desired by almost all market operators and policymakers, since oil-price movements substantially affect, at different degrees and through different channels, the performance of most economic sectors and industries (see, Lascaroux and Mignon, 2008).

We apply the proposed empirical model to the dynamics of weekly crude-oil price returns in four OPEC oil-exporting countries, namely Kuwait, Qatar, Saudi Arabia, and United Arab Emirates over the period 1997-2008. The results are broadly in line with the findings of Elder and Serletis (2008), and Alvarez-Ramirez et al. (2008) in that we show evidence of time-varying autocorrelations for weekly oil-return dynamics over the study period, except for some relatively short sub-periods. However, the hypothesis of convergence towards efficient behavior over time cannot be confirmed, since the intensity of oil-return predictability has tended to increase rather than decrease in recent years. We also performed the Bai and Perron (2003) test to investigate the effects of structural reforms on the time-path of the estimated predictability measure, and detect only one breakpoint, for Qatar, whose 95\% confidence intervals broadly cover the period of major changes in crude-oil prices following OPEC's decisions to reduce its oil production.

To the extent that oil-price increases negatively influence economic activity and that this can be predicted from their past history, it would be in the interest of policymakers to consider these features in order to develop coherent energy and economic plans. For global investors who allocate portions of their portfolios to crude and refined oil products, our results imply that short-term benefits can be obtained from an active investment strategy, while taking into account trading and transaction costs.

\section{References}


Alvarez-Ramirez, J., Alvarez, J., Rodriguez, E., 2008. Short-term predictability of crude oil markets: a detrended fluctuation analysis approach. Energy Economics, 30, 2645-2656.

Arouri, M., Rault, C., 2009. Oil prices and stock markets: what drives what in the Gulf Corporation Council countries?. William Davidson Institute, Academic Working Paper Series, No. 09.

Arouri M et Fouquau J, 2009, "On the Short-Term Influence of Oil Price Changes on Stock Markets in GCC Countries: Linear and Nonlinear Analyses ", Economics Bulletin, vol.29(2), 795-804.

Ashenwald, J., Fink, S., Tappeiner, G., 2002. Brave new modeling: cellular automata and artificial neural networks for mastering complexity in economics. Complexity, 7, 39-46.

Bai, J., Perron, P., 2003. Computation and analysis of multiple structural change models. Journal of Applied Econometrics, 18, 1-22.

Basher, S.A., Sadorsky, P., 2006. Oil price risk and emerging stock markets. Global Finance Journal, $17,224-251$.

Bollerslev, T., 1986. Generalized autoregressive conditional heteroskedasticity. Journal of Econometrics, 31, 307-327.

Boyer, M.M., Filion, D., 2007. Common and fundamental factors in stock returns of Canadian oil and gas companies. Energy Economics, 29, 428-453.

Driesprong, G., Jacobsen, B., Maat, B., 2008. Striking oil: another puzzle?. Journal of Financial Economics, 89, 307-327.

Elder, J., Serletis, A., 2008. Long memory in energy futures prices. Review of Financial Economics, $17,146-155$.

El-Sharif, I., Brown, D., Burton, B., Nixon, B., Russell, A., 2005. Evidence on the nature and extent of the relationship between oil prices and equity values in the UK. Energy Economics, 27, 819-830.

Fama, E.F, 1991. Efficient capital markets II. Journal of Finance, 46, 1575-1617.

Fama, E.F., 1970. Efficient capital markets: a review of theory and empirical work. Journal of Finance, 25, 383-417.

Fasano, U., Iqbal, Z., 2003. GCC countries: from oil dependence to diversification. IMF Working Paper, Washington, DC.

Fleming, J., Ostdiek, B., 1999. The impact of energy derivatives on the crude oil market. Energy Economics, 21, 135-167. 
Fontaine, P., Nguyen, D.K., 2006. Stock market liberalization and informational efficiency in emerging markets: new consideration and tests. Banks, Markets and Investors, 84, 6-17.

Green, S.L., Mork, K.A., 1991. Toward efficiency in the crude-oil market. Journal of Applied Econometrics, 6, 45-66.

Hamilton, J.D., 1983. Oil and the macroeconomy since World War II. Journal of Political Economy, $91,228-248$.

Hammoudeh, S., Aleisa, E., 2004. Dynamic relationship among GCC stock markets and NYMEX oil futures. Contemporary Economic Policy, 22, 250-269.

Hammoudeh, S., Li, H., 2004. Risk-return relationships in oil-sensitive stock markets. Finance Letters, $2,10-15$.

Hammoudeh, S.M, Ewing, B.T., Thompson, M.A., 2008. Threshold cointegration analysis of crude oil benchmarks. Energy Journal, 29, 79-96.

Harvey A.C., 1993. Time series models, second ed. Harvester-Wheatsheaf, New York.

Jefferis, K., Smith, G., 2005. The changing efficiency of African stock markets. South African Journal of Economics, 73, 54-73.

Jones, C.M., Kaul, G., 1996. Oil and the stock markets. Journal of Finance, 51, 463-491.

Lardic, S., Mignon, V., 2008. Oil prices and economic activity: an asymmetric cointegration approach. Energy Economics, 30, 847-855.

Lescaroux, F., Mignon, V., 2008. On the influence of oil prices on economic activity and other macroeconomic and financial variables. OPEC Energy Review, 32, 343-380.

Lo, A.W., 1991. Long-term memory in stock market prices. Econometrica, 59, 1279-1313.

Maghyereh, A., Al-Kandari, A., 2007. Oil prices and stock markets in GCC countries: new evidence from nonlinear cointegration analysis. Managerial Finance, 33, 449-460.

Maslyuk, S., Smyth, R.L., 2008. Unit root properties of crude oil spot and futures prices. Energy Policy, 36, 2591-2600.

Nandha, M., Faff, R., 2008. Does oil move equity prices? A global view. Energy Economics, 30, 986997.

Rockinger, M., Urga, G., 2000. The evolution of stock markets in transition economies. Journal of Comparative Economics, 28, 456-472. 
Serletis, A., Rangel-Ruiz, R., 2004. Testing for common features in North American energy markets. Energy Economics, 26, 401-414.

Shambora, W.E., Rossiter, R., 2007. Are there exploitable inefficiencies in the futures market for oil?. Energy Economics, 29, 18-27.

Tabak, B.M., Cajueiro, D.O., 2007. Are the crude oil markets becoming weakly efficient over time? A test for time-varying long-range dependence in prices and volatility. Energy Economics, 29, 28-36.

Zalewska-Mitura, A., Hall, S.G., 1999. Examining the first stages of market performance: a test for evolving market efficiency. Economics Letters, 64, 1-12.

Zarour, B.A., 2006. Wild oil prices, but brave stock markets! The case of Gulf Cooperation Council (GCC) stock markets. Operational Research: An International Journal, 6, 145-162.

Zhang, D., 2008. Oil shock and economic growth in Japan: a nonlinear approach. Energy Economics, $30,2374-2390$. 